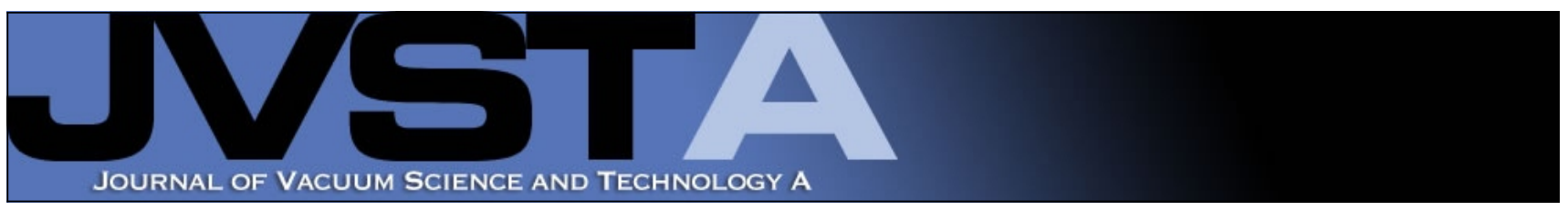

\title{
Comprehensive study of the p-type conductivity formation in radio frequency magnetron sputtered arsenic-doped $\mathrm{ZnO}$ film
}

\author{
J. C. Fan, C. Y. Zhu, B. Yang, S. Fung, C. D. Beling et al.
}

Citation: J. Vac. Sci. Technol. A 29, 03A103 (2011); doi: 10.1116/1.3525639

View online: http://dx.doi.org/10.1116/1.3525639

View Table of Contents: http://avspublications.org/resource/1/JVTAD6/v29/i3

Published by the AVS: Science \& Technology of Materials, Interfaces, and Processing

\section{Related Articles}

Modification of transparent conductive $\mathrm{ZnO}$ and $\mathrm{Ga}$-doped $\mathrm{ZnO}$ films by irradiation with electron cyclotron resonance argon plasma

J. Vac. Sci. Technol. A 29, 031304 (2011)

Effects of gallium doping on properties of a-plane $\mathrm{ZnO}$ films on r-plane sapphire substrates by plasma-assisted molecular beam epitaxy

J. Vac. Sci. Technol. A 29, 03A111 (2011)

Properties of phosphorus-doped zinc oxide films grown by pulsed laser deposition

J. Vac. Sci. Technol. A 29, 03A109 (2011)

Effective atomic layer deposition procedure for Al-dopant distribution in $\mathrm{ZnO}$ thin films

J. Vac. Sci. Technol. A 28, 1111 (2010)

Resistivity characteristics of transparent conducting impurity-doped $\mathrm{ZnO}$ films for use in oxidizing environments at high temperatures

J. Vac. Sci. Technol. A 28, 861 (2010)

\section{Additional information on J. Vac. Sci. Technol. A}

Journal Homepage: http://avspublications.org/jvsta

Journal Information: http://avspublications.org/jvsta/about/about_the_journal

Top downloads: http://avspublications.org/jvsta/top_20_most_downloaded

Information for Authors: http://avspublications.org/jvsta/authors/information_for_contributors

\section{ADVERTISEMENT}

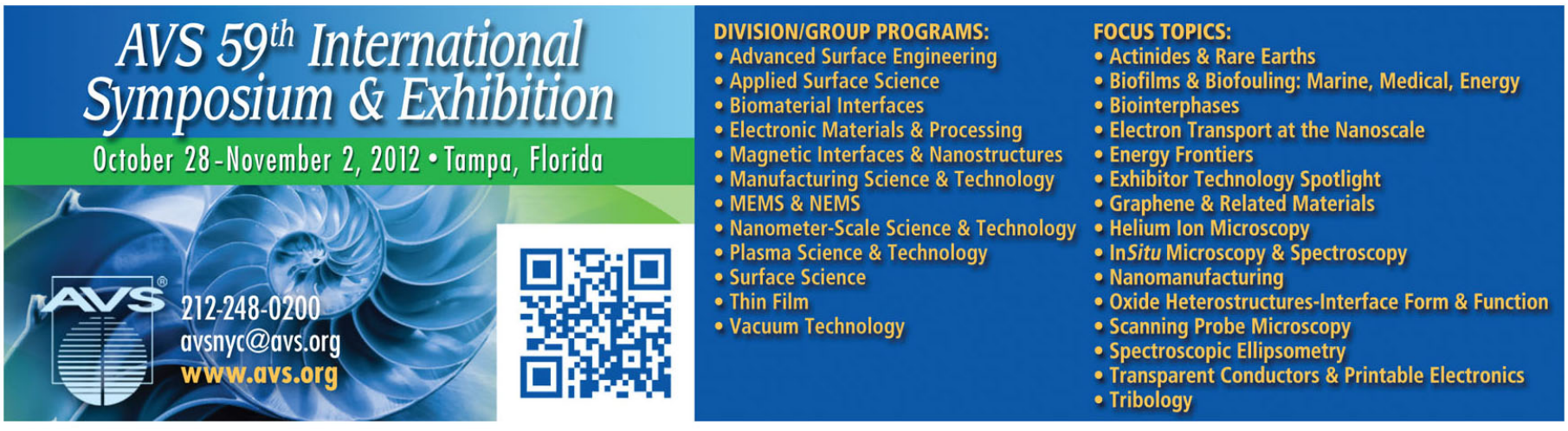




\title{
Comprehensive study of the $p$-type conductivity formation in radio frequency magnetron sputtered arsenic-doped $\mathrm{ZnO}$ film $^{\text {a) }}$
}

\author{
J. C. Fan, C. Y. Zhu, B. Yang, S. Fung, and C. D. Beling \\ Department of Physics, University of Hong Kong, Pokfulam, Hong Kong, People's Republic of China \\ G. Brauer \\ Institut für Ionenstrahlphysik und Materialforschung, Forschungszentrum Dresden-Rossendorf, 510119, \\ D-01314, Dresden, Germany \\ W. Anwand \\ Institut für Strahlenphysik, Forschungszentrum Dresden-Rossendorf, 510119, D-01314, Dresden, Germany \\ D. Grambole and W. Skorupa \\ Institut für Ionenstrahlphysik und Materialforschung, Forschungszentrum Dresden-Rossendorf, 510119, \\ D-01314, Dresden, Germany
}

K. S. Wong and Y. C. Zhong

Department of Physics, Hong Kong University of Science and Technology, Hong Kong, People's Republic of China

Z. Xie

College of Physics and Microelectronic Science, Hunan University, Changsha 410082, People's Republic of China

C. C. Ling ${ }^{\text {b) }}$

Department of Physics, University of Hong Kong, Pokfulam, Hong Kong, People's Republic of China

(Received 16 August 2010; accepted 8 October 2010; published 11 January 2011)

Arsenic doped $\mathrm{ZnO}$ and $\mathrm{ZnMgO}$ films were deposited on $\mathrm{SiO}_{2}$ using radio frequency magnetron sputtering and $\mathrm{ZnO}-\mathrm{Zn}_{3} \mathrm{As}_{2}$ and $\mathrm{ZnO}-\mathrm{Zn}_{3} \mathrm{As}_{2}-\mathrm{MgO}$ targets, respectively. It was found that thermal activation is required to activate the formation of $p$-type conductivity. Hall measurements showed that $p$-type films with a hole concentration of $\sim 10^{17} \mathrm{~cm}^{-3}$ and mobility of $\sim 8 \mathrm{~cm}^{2} \mathrm{~V}^{-1} \mathrm{~s}^{-1}$ were obtained at substrate temperatures of $400-500{ }^{\circ} \mathrm{C}$. The shallow acceptor formation mechanism was investigated using x-ray photoelectron spectroscopy, positron annihilation, low temperature photoluminescence, and nuclear reaction analysis. The authors suggest that the thermal annealing activates the formation of the $\mathrm{As}_{\mathrm{Zn}}-2 V_{\mathrm{Zn}}$ shallow acceptor complex and removes the compensating hydrogen center. () 2011 American Vacuum Society. [DOI: 10.1116/1.3525639]

\section{INTRODUCTION}

Despite many efforts, $p$-type doping of $\mathrm{ZnO}$ still remains an important issue in $\mathrm{ZnO}$-based device technology. ${ }^{1} \mathrm{ZnO}$ $p$-type doping is difficult, and the studies so far are not very reproducible and are controversial. There have been reports on the fabrication of arsenic doped $p$-type $\mathrm{ZnO}$ with hole concentrations ranging from $10^{16}$ to $10^{18} \mathrm{~cm}^{-3} \cdot{ }^{2-7}$ Theoretical calculations showed that $\mathrm{As}_{\mathrm{Zn}}$ is a donor and $\mathrm{As}_{\mathrm{O}}$ is a deep acceptor (with ionization energy $E_{i} \sim 1000 \mathrm{meV}$ ), ${ }^{8}$ and thus, they would not be the shallow acceptor responsible for the $p$-type conduction. Using first principal calculations, Limpjumnong et l. $^{8}$ showed that $\mathrm{As}_{\mathrm{Zn}}-2 V_{\mathrm{Zn}}$ could be a relatively shallow acceptor having $E_{i} \sim 150 \mathrm{meV}$ for the $(0 /+)$ ionization, and its formation from its parent defects $\mathrm{As}_{\mathrm{Zn}}$ and $V_{\mathrm{Zn}}$ was energetically favorable. Tentative assignment of this complex to the shallow acceptors in the As-doped $p$-type $\mathrm{ZnO}$ materials has thus been proposed.

\footnotetext{
${ }^{\text {a) }}$ This article is based on material presented at the 6th International Workshop on Zinc Oxide and Related Materials.

${ }^{b)}$ Electronic mail: ccling@hku.hk
}

In the present study, using the radio frequency magnetron sputtering method, we have fabricated As-doped $p$-type $\mathrm{ZnO}$ films on $\mathrm{SiO}_{2}$ with a hole concentration ranging between $\sim 10^{17}$ and $10^{18} \mathrm{~cm}^{-3}$ and hole mobility of $\sim 8 \mathrm{~cm}^{2} \mathrm{~V}^{-1} \mathrm{~s}^{-1}$. We used x-ray diffraction (XRD), x-ray photoelectron spectroscopy (XPS), low temperature photoluminescence (PL), positron annihilation spectroscopy (PAS), and nuclear reaction analysis (NRA) to systematically investigate the shallow acceptor formation mechanism in As-doped $p$-type $\mathrm{ZnO}$ as well as the effects of thermal annealing.

\section{EXPERIMENT}

The $\mathrm{ZnO}$ films were fabricated using radio frequency magnetron sputtering at $10^{-3} \mathrm{~Pa}$ and using radio frequency power of $120 \mathrm{~W}$. The films were deposited on to $250 \mathrm{~nm}$ thick $\mathrm{SiO}_{2}$ grown on $\mathrm{Si}$ substrates thermally in dry oxygen. The As-doped $\mathrm{ZnO}$ films were grown by using a ceramic target containing $\mathrm{Zn}_{3} \mathrm{As}_{2}$ (molecular ratio of $1 \mathrm{~mol} \%$ ) and $\mathrm{ZnO}$ (molecular ratio of $99 \mathrm{~mol} \%$ ). The As-doped $\mathrm{ZnMgO}$ films were sputtered from a ceramic target containing $\mathrm{ZnO}$, $\mathrm{MgO}$, and $\mathrm{Zn}_{3} \mathrm{As}_{2}$, having the molecular ratios of 97.5 at. \%, 
$1.5 \mathrm{~mol} \%$, and $1.0 \mathrm{~mol} \%$, respectively. The substrate temperature during growth was varied as necessary.

The carrier concentrations of the samples at room temperature were obtained by Hall effect using the BioRad HL5500 system using the van der Waal's configuration. In order to investigate the reproducibility of the growth, the carrier types and concentrations with varying growing parameters for the As-doped $\mathrm{ZnO}$ samples (i.e., the substrate temperature) were obtained by averaging the measurements from samples produced from at least five independent growths. Details of the XRD, XPS, PL, and PAS measurements could be found in Ref. 7, and those of the NRA measurement were given in Ref. 9.

\section{RESULTS AND DISCUSSION}

Control samples fabricated by using a pure ceramic $\mathrm{ZnO}$ target (no arsenic) and similar growing parameters were grown using a substrate temperature of $450{ }^{\circ} \mathrm{C}$. The control sample had electron concentrations of $\sim 6 \times 10^{18} \mathrm{~cm}^{-3}$ and electron mobility of $17 \mathrm{~cm}^{2} \mathrm{~V} \mathrm{~s}^{-1}$. As-doped $\mathrm{ZnO}$ and $\mathrm{Zn}$ $\mathrm{MgO}$ samples were grown on the $\mathrm{SiO}_{2}$ substrates with the substrate temperatures varying from 200 to $500{ }^{\circ} \mathrm{C}$. XRD measurements were carried out to obtain the structural information on these samples. Single peaks at $\sim 2 \theta$ $=34.35^{\circ}-34.52^{\circ}(\mathrm{ZnO}[002]$ direction $)$ were observed in the XRD spectra of As-doped $\mathrm{ZnO}$ samples grown at substrate temperatures of 200,400 , and $450{ }^{\circ} \mathrm{C}$, which implied that these conditions yielded films with single phase wurtzite structure with $c$-axis orientation. For the As-doped $\mathrm{ZnO}$ sample grown at $500{ }^{\circ} \mathrm{C}$ substrate temperature, other than the $\mathrm{ZnO}$ (002) peak, small peaks corresponding to $\mathrm{ZnO}$ (100) and $\mathrm{ZnO}(110)$ were also found. For the case of As-doped $\mathrm{ZnMgO}$ samples grown at all the substrate temperatures, single peaks at $\sim 34.46^{\circ}$ ( $\mathrm{ZnO}[002]$ direction) were observed in the corresponding XRD spectra.

Secondary ion mass spectroscopy (SIMS) measurements were also carried out on the As-doped $\mathrm{ZnO}$ and $\mathrm{ZnMgO}$ samples grown at $450{ }^{\circ} \mathrm{C}$. Arsenic was found to be uniformly present in both films, and uniform $\mathrm{Mg}$ distribution was observed in the $\mathrm{ZnMgO}$ film. The film thickness was $\sim 280 \mathrm{~nm}$. Calibrated with an As-implanted sample with known fluence, the As concentration in these films was $\sim 10^{19} \mathrm{~cm}^{-3}$.

The carrier concentrations in the As-doped $\mathrm{ZnO}$ and $\mathrm{Zn}$ $\mathrm{MgO}$ samples are plotted against the growth temperature in Fig. 1. The samples were $n$-type at low growth temperatures and transited to $p$-type as the substrate temperature was increased. This trend was common to both $\mathrm{ZnO}$ and $\mathrm{ZnMgO}$ samples. This indicated that the formation of $p$-type conduction involves a thermal activation process. We have also performed a postgrowth annealing study in Ar on the As-doped $\mathrm{ZnO}$ sample grown at the substrate temperature of $200{ }^{\circ} \mathrm{C}$, which was $n$-type prior to annealing. The sample was found to convert from $n$-type $\left(n=5 \times 10^{16} \mathrm{~cm}^{-3}\right)$ to $p$-type $(p=2$ $\times 10^{16} \mathrm{~cm}^{-3}$ ) after the $400{ }^{\circ} \mathrm{C}$ postgrowth annealing. The hole concentration further increased to $\left(p=3 \times 10^{16} \mathrm{~cm}^{-3}\right)$ as the annealing temperature was further increased to $500{ }^{\circ} \mathrm{C}$.

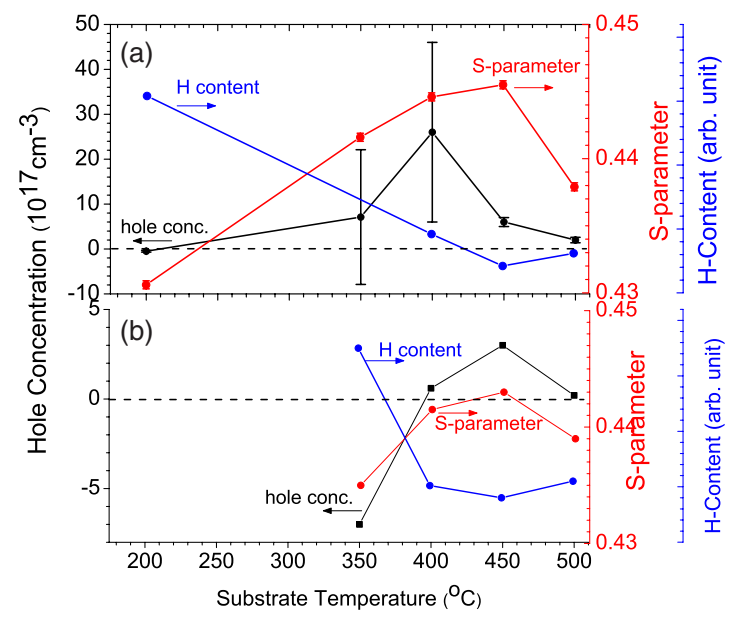

FIG. 1. (Color online) Hole concentration, $S$-parameter and hydrogen content as a function of the growth substrate temperature for (a) the As-doped $\mathrm{ZnO}$ sample and (b) the As-doped $\mathrm{ZnMgO}$ sample.

These results definitely confirmed that thermal activation is required for the formation of $p$-type conduction. It was noticed that a hole concentration of $10^{17}-10^{18} \mathrm{~cm}^{-3}$ and a hole mobility of 1-8 $\mathrm{cm}^{2} \mathrm{~V}^{-1} \mathrm{~s}^{-1}$ were obtained for the Asdoped samples grown at substrate temperatures of $400-450{ }^{\circ} \mathrm{C}$.

The low temperature $(T=10 \mathrm{~K})$ near band edge PL spectra of the undoped $\mathrm{ZnO}$, As-doped $n$-type $\mathrm{ZnO}$ (grown at substrate temperature of $200{ }^{\circ} \mathrm{C}$ ), As-doped $p$-type $\mathrm{ZnO}$, and $\mathrm{ZnMgO}$ (both grown at $450{ }^{\circ} \mathrm{C}$ of substrate temperature) are shown in Fig. 2. Three major peaks at 3.234, 3.308, and $3.355 \mathrm{eV}$ were observed in the undoped $\mathrm{ZnO}$ sample PL spectrum. Emission lines with similar peak positions have also been observed from $n$-type $\mathrm{ZnO}$ prepared by sol-gel method $^{10}$ and from $\mathrm{ZnO}$ tetrapods. ${ }^{11}$ These emissions at $3.234,3.308$, and $3.355 \mathrm{eV}$ peaks are attributed respectively to the donor-acceptor-pair (DAP) emission, two-electronsatellite and/or exciton-LO phonon emission, and $D_{0} X$ emission. Five major PL peaks were found in the As-doped p-type $\mathrm{ZnO}$ sample at 3.158, 3.197, 3.236, 3.282, and 3.337 $\mathrm{eV}$. The 3.158, 3.197, and $3.236 \mathrm{eV}$ were attributed to DAP

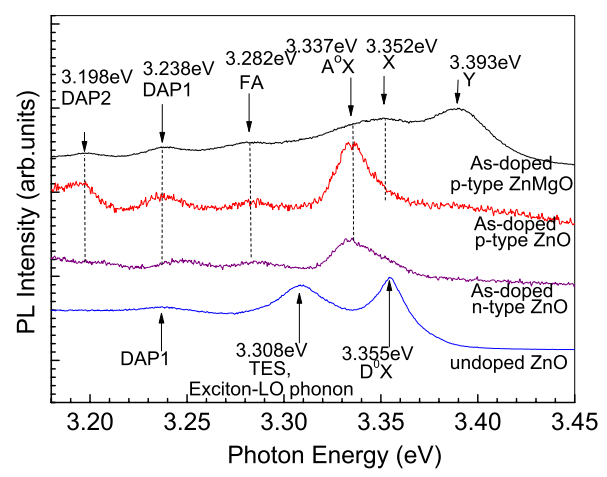

FIG. 2. (Color online) Near band edge PL spectra of the As-doped $p$-type $\mathrm{ZnMgO}$ (substrate temperature $=450{ }^{\circ} \mathrm{C}$ ), As-doped $p$-type $\mathrm{ZnO}$ (substrate temperature $=450{ }^{\circ} \mathrm{C}$ ), As-doped $n$-type $\mathrm{ZnO}$ (substrate temperature $=200{ }^{\circ} \mathrm{C}$ ), and the undoped $\mathrm{ZnO}$ samples measured at $10 \mathrm{~K}$. 


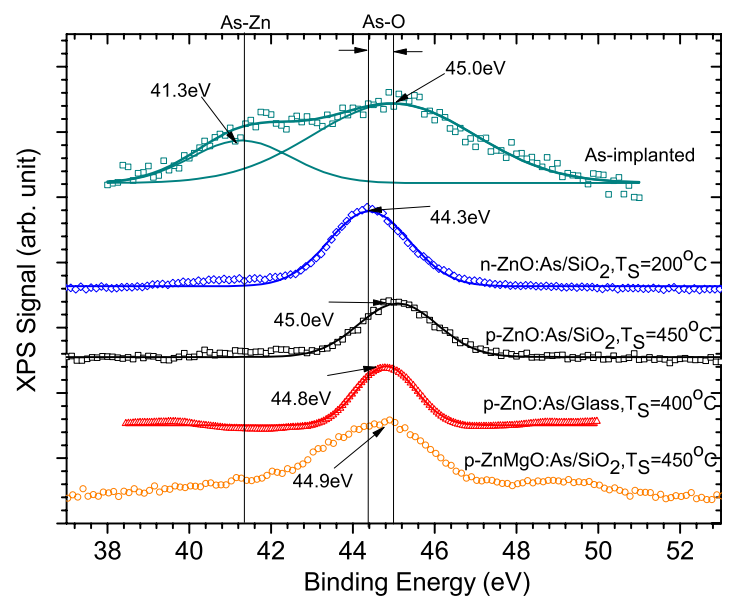

FIG. 3. (Color online) As $3 d$ binding energy of the XPS spectra for the As-implanted sample and the different As-doped $\mathrm{ZnO}$ and $\mathrm{ZnMgO}$ samples.

emissions. The other two peaks at 3.282 and $3.337 \mathrm{eV}$ were only observed in the $p$-type $\mathrm{ZnO}$ and $\mathrm{ZnMgO}$ samples and also in the $p$-type As-doped $\mathrm{ZnMgO}$ sample. They were attributed to free electron to acceptor (FA) emission and acceptor-bound exciton $\left(A_{0} X\right)$ emission, respectively. ${ }^{2,6,12}$ Taking the FA emission line energy $E_{\mathrm{FA}}=3.282 \mathrm{eV}$ and $E_{g}$ $=3.437 \mathrm{eV},{ }^{13}$ the activation energy $E_{A}$ of the corresponding acceptor can be calculated using $E_{A}=E_{g}-E_{\mathrm{FA}}+k T / 2$. This yields $E_{A}=155 \mathrm{meV}$.

Figure 3 shows the As $(3 d)$ XPS spectra of the As-doped $n$-type sample grown at $200{ }^{\circ} \mathrm{C}$, the As-doped $p$-type $\mathrm{ZnO}$ and $\mathrm{ZnMgO}$ samples both grown at $450{ }^{\circ} \mathrm{C}$. A dominant peak at $\sim 45 \mathrm{eV}$ was found in all these As-doped samples. The binding energy of $45 \mathrm{eV}$ is close to the previously reported value of the As-O bond, ${ }^{14}$ and thus, this peak is attributed to the As atom substituting the $\mathrm{Zn}$ site (i.e., $\mathrm{As}_{\mathrm{Zn}}$ ) in the $\mathrm{ZnO}$ lattice. We have also carried out the XPS measurements on the as-As-implanted $\mathrm{ZnO}$ sample and on the Asimplanted $\mathrm{ZnO}$ sample after the $750{ }^{\circ} \mathrm{C}$ postimplantation $\mathrm{Ar}$ annealing. ${ }^{15}$ The implantation energy was $100 \mathrm{keV}$, which corresponded to an implantation depth extending to $\sim 100 \mathrm{~nm}$ (obtained from TRIM calculation and SIMS measurement). We have attempted the As-implantation fluences of $10^{14}$ and $10^{15} \mathrm{~cm}^{-2}$, which corresponded to Asconcentrations of $\sim 10^{19}-10^{20} \mathrm{~cm}^{-3}$. Despite successful fabrication of light emitting diodes operating at room temperature using the ion-implantation technique followed with postimplantation annealing, ${ }^{16}$ no rectifying $I V$-behavior and thus no hint of $p$-type layer formation was observed in these As-implanted samples. The XPS spectrum of the as-Asimplanted sample is also included in Fig. 3, and the XPS spectrum for the As-implanted sample annealed at $750{ }^{\circ} \mathrm{C}$ was similar. Two peaks $\sim 41$ and $45 \mathrm{eV}$ were found. The 41 $\mathrm{eV}$ peak is attributed to the As- $\mathrm{Zn}$ bond ${ }^{14}$ and thus was originated from the $\mathrm{As}_{\mathrm{O}}$ defect site.

Using PAS as a selective probe sensitive to vacancy type defects, we investigated the Zn-vacancy related defects in the As-doped $\mathrm{ZnO}$ and $\mathrm{ZnMgO}$ samples grown at different substrate temperatures. PAS is based on the annihilation of inci- dent positrons with electrons in the sample, and subsequent emission and detection of $511 \mathrm{keV}$ gamma photons. ${ }^{17,18}$ As a vacancy type defect presents as a potential well to the thermalized positron, the diffusing positron would be trapped by such open volume defects. The Doppler broadening of the $511 \mathrm{keV}$ peak (parametrized by the $S$-parameter) is determined by the electronic environment in which the positron annihilates and thus the information about the corresponding vacancy state in the sample could be revealed. For the case of $\mathrm{ZnO}$, only the $\mathrm{Zn}$-vacancy related defects would trap positron but not the O-vacancy. ${ }^{9}$ This implies that the variation of the observed $S$-parameter is a result of the change of the $Z n$-vacancy related defect. The increase of $S$-parameter corresponds with the increase of the open volume and/or the concentration of the relevant vacancy type defect. The $S$-parameters of the As-doped $\mathrm{ZnO}$ and $\mathrm{ZnMgO}$ samples as a function of growth substrate temperature are shown in Fig. 1. A strong correlation between the $S$-parameter and the rise of the hole concentration with increasing substrate temperature was observed in both types of samples. This implied an increase of the open volume and/or the concentration of the $\mathrm{Zn}$-vacancy type defects in the $\mathrm{ZnO}$ and the $\mathrm{ZnMgO}$ samples while the substrate temperature was raised.

Figure 1 also shows the $H$-concentrations in the As-doped $\mathrm{ZnO}$ and $\mathrm{ZnMgO}$ samples as a function of the substrate temperature. $H$-concentrations were obtained using NRA. An anticorrelation between the $H$ concentration and the hole concentration was clearly found in both types of sample.

PL-data showed that the shallow acceptor had an activation energy of $E_{A}=155 \mathrm{meV}$, which was very close to the calculated ionization energy $E_{i}=150 \mathrm{meV}$ for the $(0 /+)$ ionization of the $\mathrm{As}_{\mathrm{Zn}}-2 V_{\mathrm{Zn}}$ acceptor complex. The XPS data showed that the majority of the As-atoms introduced into the films occupied the $\mathrm{As}_{\mathrm{Zn}}$ site in the $\mathrm{ZnO}$ lattice, although it was not possible to distinguish whether the $\mathrm{As}_{\mathrm{Zn}}$ structure involved was part of the $\mathrm{As}_{\mathrm{Zn}}-2 V_{\mathrm{Zn}}$ complex or it was the isolated $\mathrm{As}_{\mathrm{Zn}}$. From the experimental data, the formation of the $p$-type conductivity was associated with thermal excitation and was correlated with the increase of the $S$-parameter, i.e., the open volume and/or the concentration of the relevant Zn-vacancy related defects. Limpijumnong et al. ${ }^{8}$ pointed out that for the shallow acceptor complex $A_{\mathrm{Zn}}-2 V_{\mathrm{Zn}}$, the As-O bond adjacent to the $V_{\mathrm{Zn}}$ would be shortened by $5 \%{ }^{8}$ This implied that the adjacent $V_{\mathrm{Zn}}$ would have a larger open volume. Thus, the observation of the increase of $S$-parameter is in agreement with the formation of the $\mathrm{As}_{\mathrm{Zn}}-2 V_{\mathrm{Zn}}$ complex. With these observations, we tentatively ascribe the observed $p$-type conductivity in our $p$-type As-doped $\mathrm{ZnO}$ and $\mathrm{ZnMgO}$ samples to the $\mathrm{As}_{\mathrm{Zn}}-2 V_{\mathrm{Zn}}$ complex.

It is also worth pointing out that the shallow acceptor related emission PL lines $A_{0} X$ and $F X$ were found in the As-doped $\mathrm{ZnO}$ sample fabricated at a low substrate temperature of $200{ }^{\circ} \mathrm{C}$, although the sample was highly resistive but $n$-type conducting. This implied that some relevant shallow acceptors have already been formed and thus the resistive $n$-type conduction was probably due to the compensation by other defects. Our NRA data showed that hydrogen was gen- 
erally present in all the As-doped $\mathrm{ZnO}$ and $\mathrm{ZnMgO}$ samples. Hydrogen impurity acting as donor would compensate the $p$-type conductivity. The $p$-type conductivity was thus enhanced with the thermal removal of the hydrogen compensating center as revealed by the NRA measurement.

\section{SUMMARY AND CONCLUSIONS}

As-doped $\mathrm{ZnO}$ and $\mathrm{ZnMgO}$ films were grown on $\mathrm{SiO}_{2}$ at different substrate temperatures. It was found that thermal activation was needed to introduce the $p$-type conduction in these films. The thermal process was probably associated with the formation of the $\mathrm{As}_{\mathrm{Zn}}-2 V_{\mathrm{Zn}}$ shallow acceptor complex and the removal of the compensating hydrogen impurity.

\section{ACKNOWLEDGMENTS}

The work presented here was supported under the General Research Fund (Contract No. 7031/08P), Research Grant Council, HKSAR, the Small Project Funding, and the University Development Fund, The University of Hong Kong.

${ }^{1}$ Ü. Özgür, Ya. I. Alivov, C. Liu, A. Teke, M. A. Reshchikov, S. Doğan, V. Avrutin, S.-J. Cho, and H. Morkoç, J. Appl. Phys. 98, 041301 (2005).

${ }^{2}$ Y. R. Ryu, T. S. Lee, and H. W. White, Appl. Phys. Lett. 83, 87 (2003).
${ }^{3}$ D. C. Look, G. M. Renlund, R. H. Burgener, and J. R. Sizelove, Appl. Phys. Lett. 85, 5269 (2004).

${ }^{4}$ G. Braunstein, A. Muraviev, H. Saxena, N. Dhere, V. Richter, and R. Kalish, Appl. Phys. Lett. 87, 192103 (2005).

${ }^{5}$ V. Vaithianathan, B.-T. Lee, and S. S. Kim, Appl. Phys. Lett. 86, 062101 (2005).

${ }^{6}$ H. S. Kang, G. H. Kim, D. L. Kim, H. W. Chang, B. D. Ahn, and S. Y. Lee, Appl. Phys. Lett. 89, 181103 (2006).

${ }^{7}$ J. C. Fan et al., J. Appl. Phys. 106, 073709 (2009).

${ }^{8}$ S. Limpijumnong, S. B. Zhang, S.-H Wei, and C. H. Park, Phys. Rev. Lett. 92, 155504 (2004).

${ }^{9}$ G. Brauer et al., Phys. Rev. B 79, 115212 (2009).

${ }^{10}$ J. Petersen et al., J. Appl. Phys. 104, 113539 (2008).

${ }^{11}$ Y. Zhong, A. B. Djurišić, Y. F. Hsu, K. S. Wong, G. Brauer, C. C. Ling, and W. K. Chan, J. Phys. Chem. C 112, 16286 (2008).

${ }^{12}$ D. C. Look and B. Claflin, Phys. Status Solidi B 241, 624 (2004).

${ }^{13}$ D.-K. Hwang, H.-S. Kim, J.-H. Lim, J.-Y. Oh, J.-H. Yang, S.-J. Park, K.-K. Kim, D. C. Look, and Y. S. Park, Appl. Phys. Lett. 86, 151917 (2005).

${ }^{14}$ C. D. Wagner, W. M. Riggs, L. E. Davis, J. F. Moulder, and G. E. Muilenberg, in Handbook of X-ray Photoelectron Spectroscopy, in edited by G. E. Muilenberg (Perkin Elmer, Eden Prairie, MN, 1979).

${ }^{15}$ C. Y. Zhu, C. C. Ling, G. Brauer, W. Anwand, and W. Skorupa, Microelectron. J. 40, 286 (2009).

${ }^{16}$ Q. L. Gu et al., Appl. Phys. Lett. 92, 222109 (2008).

${ }^{17}$ R. Krause-Rehberg and H. S. Leipner, in Positron Annihilation in Semiconductors: Defect Studies, (Springer, Berlin, 1999).

${ }^{18}$ Positron Beams and Their Applications, edited by P. Coleman (World Scientific, Singapore, 2000). 